\title{
Influence of different high pressure die casting processes on 3D porosity distribution of Mg-3.0Nd-0.3Zn-0.6Zr alloy
}

\author{
Yi-hu Ma', *Wen-bo Yu', Yu-qi Zhou'², Shou-mei Xiong' \\ 1. Center of Materials Science and Engineering, School of Mechanical and Electronic Control Engineering, Beijing Jiaotong University, \\ Beijing 100044, China \\ 2. School of Materials Science and Engineering, Tsinghua University, Beijing 100084, China
}

\begin{abstract}
D reconstruction was adopted to characterize the microstructural morphologies of $\mathrm{Mg}-3.0 \mathrm{Nd}-0.3 \mathrm{Zn}$ $0.6 \mathrm{Zr}$ alloy castings produced by high pressure die casting (HPDC) processes with different parameters, including low slow-shot speed, solidification pressurization and fast slow-shot speed. At low slow-shot speeds of $0.1 \mathrm{~m} \cdot \mathrm{s}^{-1}$, $0.2 \mathrm{~m} \cdot \mathrm{s}^{-1}$ and $0.3 \mathrm{~m} \cdot \mathrm{s}^{-1}$, the porosity is concentrated in the center of the castings with one spiral staggered shape along the liquid flow direction. The porosity volume simultaneously decreases with the reduction of quantity and size of externally solidified crystals (ESCs), while the shrinkage pores become more and more dispersed with the increasing low slow-shot speed. Pressurization not only reduces the porosity volume due to the improvement of feeding ability, but also transformes the center gathered porosity into one layer-by-layer distribution form. Accompanied with the increasing fast slow-shot speed, the central porosity dramatically decreases and transforms into a large-scale spiral staggered shape along the liquid flow direction. However, the porosity is much more dispersed when the speed is increased from $2 \mathrm{~m} \cdot \mathrm{s}^{-1}$ to $3 \mathrm{~m} \cdot \mathrm{s}^{-1}$.
\end{abstract}

Key words: HPDC parameters; porosity volume; 3D morphology

CLC numbers: TG146.22 Document code: A

Article ID: 1672-6421(2021)06-521-08

\section{Introduction}

Due to its accurate casting dimension and few postprocessing requirements, high pressure die casting (HPDC) process is regarded as the first choice for automotive cast components of magnesium alloys, such as AZ series magnesium alloys ${ }^{[1-3]}$. However, drawbacks including low strength at room temperature and poor corrosion resistance significantly limit its further application in industry. For further application in industry, it is necessary to analyze their microstructures obtained by different HPDC processes.

Generally, the defects observed in HPDC castings, such as gas pores, shrinkage pores, defect bands and

\section{*Wen-bo Yu}

Male, $\mathrm{Ph}$. D. His research interests mainly focus on magnesium matrix composites, fiber reinforced titanium aluminum laminated materials, ternary MAX phases and aluminum magnesium light alloy molding technology. He has presided over and participated in 4 national funds, 3 provincial and ministerial funds projects, as well as a number of university talent funds and schoolenterprise cooperation projects. To date, he has published more than $50 \mathrm{SCl}$ papers.

E-mail: wbyu@bjtu.edu.cn

Received: 2021-04-01; Accepted: 2021-05-17 externally solidified crystals (ESCs), are interacted with each other under different process parameters ${ }^{[4-5]}$. For example, a longer vacuum time is obtained through decreasing the low slow-shot speed, while more and larger ESCs form in the melt flow. In the end, a higher shrinkage porosity volume would form among the ESCs in castings ${ }^{[6]}$. It has been confirmed that porosity is an important detrimental factor that could significantly deteriorate the mechanical properties of castings ${ }^{[7-9]}$. For example, Song et al. ${ }^{[9]}$ and Biswas et al. ${ }^{[10]}$ reported that the porosity volume fraction could regulate the strength and elongation of the HPDC AZ91 magnesium alloy. Even though the introduction of a vacuum could almost eliminate the gas pores ${ }^{[11]}$, Li et al. ${ }^{[7]}$ pointed out that the crack initiated either from shrinkage pores connected with gas pores or the large complex shrinkage pores induced by ESCs. In comparison with 2D observation, such as a scanning electron microscope, synchrotron radiation X-ray CT technology could visualize the threedimensional size and geometry of pores in materials. With help of X-ray CT technology, Zhang et al. ${ }^{[6]}$ found that the pores could be classified into four types based on their shapes in HPDC castings, including gas pore (round), net-shrinkage (large in size and irregular, 
generally close to ESC aggregation), gas-shrinkage pore (a round pore connected by irregular shrinkage pore) and islandshrinkage (small in size and regular, at the condition of a few ESCs aggregated). Lee et al. ${ }^{[12]}$ found that the defect band was composed of large and irregular porosities, which played the role of crack initiation site and propagation route. Yu et al. ${ }^{[14]}$ revealed that the defect band width was strongly related to the size and quantity of ESCs. These observations indicate that the porosities in the defect band are related to the size and quantity of ESCs. Herein, with the help of X-ray CT technology, it is possible to regulate defect band and porosity distribution through optimizing the HPDC process.

Zhou et al. ${ }^{[15]}$ found the decrease of ESCs quantity and size can improve both strength and elongation of the $\mathrm{Mg}$ $3.0 \mathrm{Nd}-0.3 \mathrm{Zn}-0.6 \mathrm{Zr}$ alloy through the modification of runner design. However, few studies can be found about the influences of different parameters, such as low slow-shot speed, fast slow-shot speed and injection pressure, on the Mg-3.0Nd$0.3 \mathrm{Zn}-0.6 \mathrm{Zr}$ alloy. In this study, castings were prepared with different designed HPDC parameters, and their microstructures were analyzed. As porosity distribution and volume are the important factors that could significantly influence the mechanical properties, X-ray CT 3D reconstruction technology was adopted to observe their distribution.

\section{Experimental procedure}

A Mg-3.0Nd-0.3Zn-0.6Zr alloy was chosen and its chemical composition is given in Table 1 . The specimens were produced through a vacuum-assisted TOYO 350 ton die casting machine, as schematically shown in Fig. 1(a). The low-speed process was divided into two parts: the plunger first moved at a low slow-shot speed, and then moved at a fast-shot speed before pushing the melt into the die cavity. The distances which the plunger moved in the shot sleeve with slow and fast slow-shot speed are further marked in Fig. 1(a). The details of the seven HPDC procedures are listed in Table 2.

The middle part of the bar, as marked by a black square in Fig. 1(b), was taken for metallographic observation. The specimens were carefully polished on a Struers Roto Pol-22 polishing machine and ultrasonically cleaned, followed by optical microscopy (OM) and scanning electron microscopy (SEM) observation. To reconstruct the $3 \mathrm{D}$ real structure,

Table 1: Chemical composition of Mg-3.0Nd-0.3Zn-0.6Zr alloy

\begin{tabular}{ccccccc}
$\mathrm{Nd}$ & $\mathrm{Zr}$ & $\mathrm{Zn}$ & $\mathrm{Al}$ & $\mathrm{Ca}$ & $\mathrm{Fe}$ & $\mathrm{Mg}$ \\
\hline 2.86 & 0.595 & 0.256 & 0.046 & 0.029 & 0.003 & $\mathrm{Bal}$.
\end{tabular}

(a)

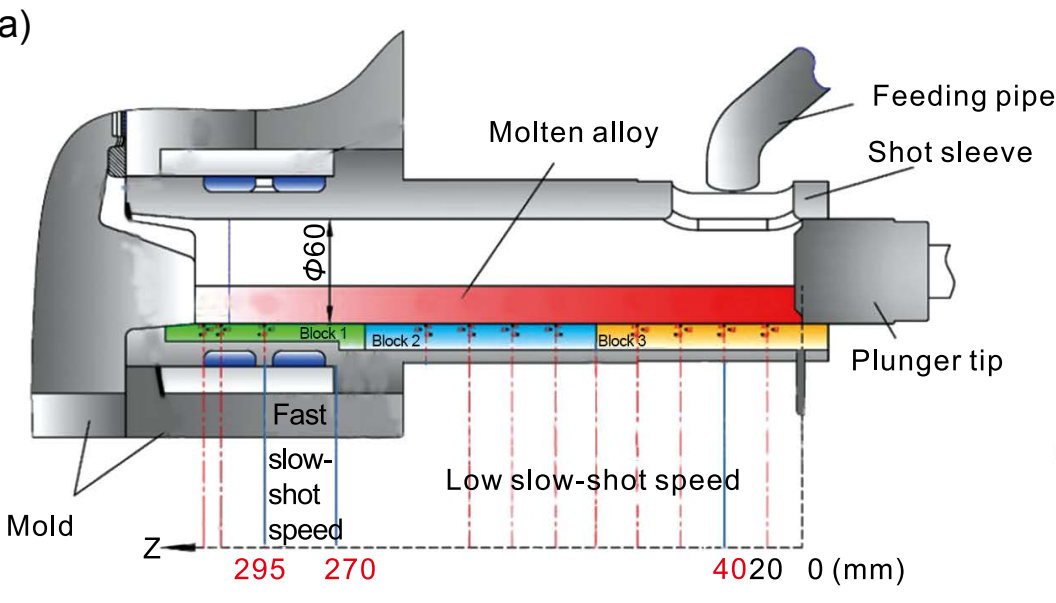

(b)

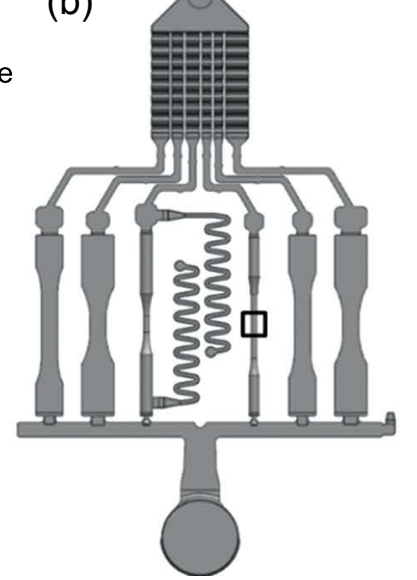

Fig. 1: Schematic of experimental setup of shot sleeve (a) and configuration of the casting (b)

Table 2: Parameters of vacuum-assisted HPDC process

\begin{tabular}{cccc} 
Specimen & $\begin{array}{c}\text { Low slow-shot } \\
\text { speed }\left(\mathrm{m} \cdot \mathrm{s}^{-1}\right)\end{array}$ & $\begin{array}{c}\text { Fast slow-shot } \\
\text { speed }\left(\mathrm{m} \cdot \mathrm{s}^{-1}\right)\end{array}$ & $\begin{array}{c}\text { Injection } \\
\text { pressure }(\mathrm{MPa})\end{array}$ \\
1 & 0.1 & 0 & 0 \\
2 & 0.2 & 0 & 0 \\
3 & 0.3 & 0 & 0 \\
4 & 0.1 & 2.0 & 0 \\
5 & 0.1 & 1.0 & 13.7 \\
6 & 0.1 & 2.0 & 13.7 \\
7 & 0.1 & 3.0 & 13.7 \\
\hline
\end{tabular}

synchrotron X-ray micro-tomography experiment was carried out at Shanghai Synchrotron Radiation Facility. The energy of X-ray is $16 \mathrm{keV}$, and the image pixel is $2048 \times 2048$. Avizo software was used to analyze the pore structure of specimens and record the data of pores. The detected pore volume should be larger than $5 \mu \mathrm{m}^{3}$.

\section{Results}

\subsection{Influence of low slow-shot speed on microstructure}

As shown in Fig. 2, the HPDC Mg-3.0Nd-0.3Zn-0.6Zr alloy mainly comprises primary $\alpha-\mathrm{Mg}$ grains (dark gray), ESCs and divorced eutectic $\mathrm{Mg}_{12} \mathrm{Nd}$ (white) at the grain boundary. 
Figure 3 represents the 3D dimensional porosity distribution in Specimens 1, 2 and 3 produced under the conditions of different low slow-shot speeds $\left(0.1,0.2\right.$ and $\left.0.3 \mathrm{~m} \cdot \mathrm{s}^{-1}\right)$, and without fast slow-shot speed and solidification pressurization. The porosity is concentrated in the center of the casting with one spiral staggered shape along the liquid flow direction, especially at $0.1 \mathrm{~m} \cdot \mathrm{s}^{-1}$ and $0.2 \mathrm{~m} \cdot \mathrm{s}^{-1}$. At $0.3 \mathrm{~m} \cdot \mathrm{s}^{-1}$, the porosity became much less and dispersed. This phenomenon is also

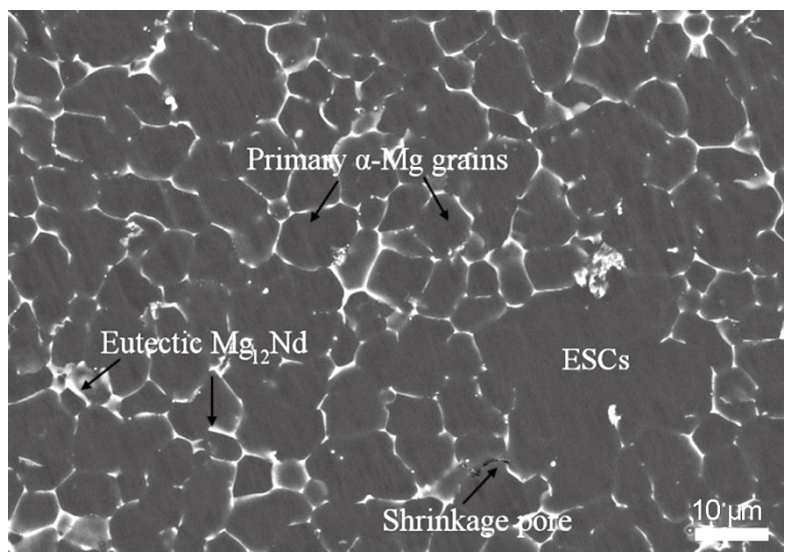

Fig. 2: Back-scattered electron image of vacuum-assist HPDC Mg-3.0Nd-0.3Zn-0.6Zr alloy found in OM images of the cross sections, as shown in Fig. 4. At $0.1 \mathrm{~m} \cdot \mathrm{s}^{-1}$, accumulated shrinkage pores form huge cavities without the formation of a defect band. Different from Specimen 1, two defect bands are found at $0.2 \mathrm{~m} \cdot \mathrm{s}^{-1}$ (Specimen 2), in which the inner-side defect band is mainly consisted of the accumulated pores. Continuously, the shrinkage pores become more dispersed when the low slow-shot speed increases to $0.3 \mathrm{~m} \cdot \mathrm{s}^{-1}$.

Great effort and work has proved that a low slow-shot speed in shot sleeve favors the growth of ESCs ${ }^{[16]}$ and the content of ESCs is an inverse proportional function of the slow-shot speed. When the low slow-shot speed increases from $0.1 \mathrm{~m} \cdot \mathrm{s}^{-1}$ to $0.2 \mathrm{~m} \cdot \mathrm{s}^{-1}$ and $0.3 \mathrm{~m} \cdot \mathrm{s}^{-1}$, as shown in Fig. 5, the dimension of dendrite ESCs gradually decreases from $60 \mu \mathrm{m}$ to $28 \mu \mathrm{m}$ and $9 \mu \mathrm{m}$. This phenomena was also found in the study of HPDC A390 aluminum alloy, in which the primary silicon size had an inverse binary functional relationship with low slow-shot speeds ${ }^{[17]}$. Subsequently, more ESCs accumulate, and then bigger gaps appear between the crystals. It becomes more difficult for the remaining melt to fully fill these gaps and thus much more porosity forms. As shown in Fig. 6, the porosity volume decreases from $0.8 \mathrm{~mm}^{3}$ to $0.59 \mathrm{~mm}^{3}$ when the low slowshot speed increases from $0.1 \mathrm{~m} \cdot \mathrm{s}^{-1}$ to $0.2 \mathrm{~m} \cdot \mathrm{s}^{-1}$. However, the porosity volume slightly increases to $0.62 \mathrm{~mm}^{3}$ when the low

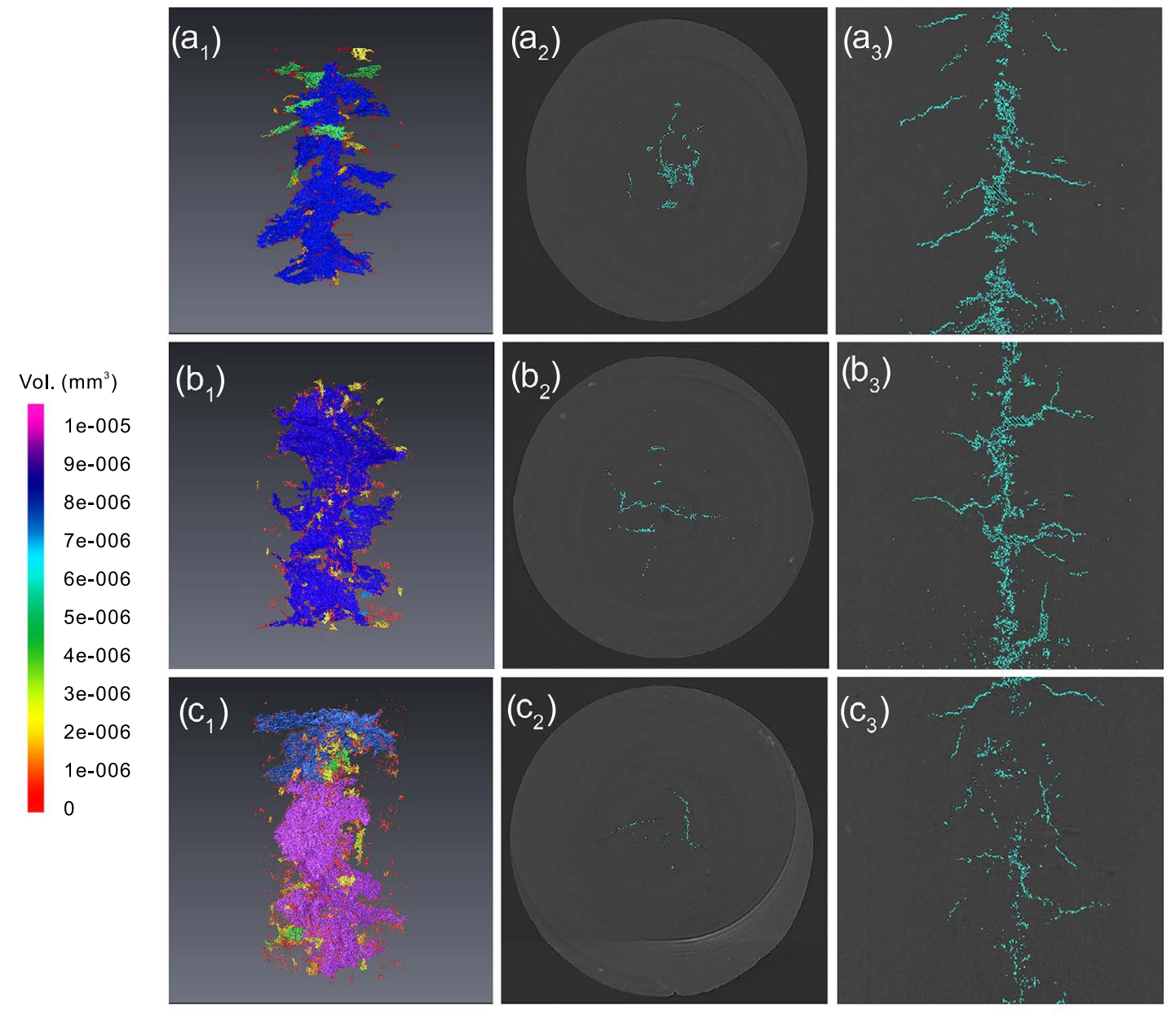

Fig. 3: 3D morphology of specimens under conditions of different low slow-shot speeds $\left(0.1,0.2\right.$ and $\left.0.3 \mathrm{~m} \cdot \mathrm{s}^{-1}\right)$ and without fast slow-shot speed and solidification pressurization $\left(a_{1}-c_{1}\right)$, cylinder section $\left(a_{2}-c_{2}\right)$, axial section along the metal flow direction $\left(a_{3}-c_{3}\right)$ 
(a)

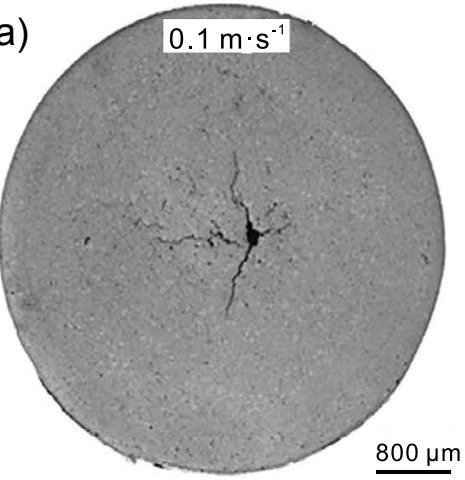

(b)

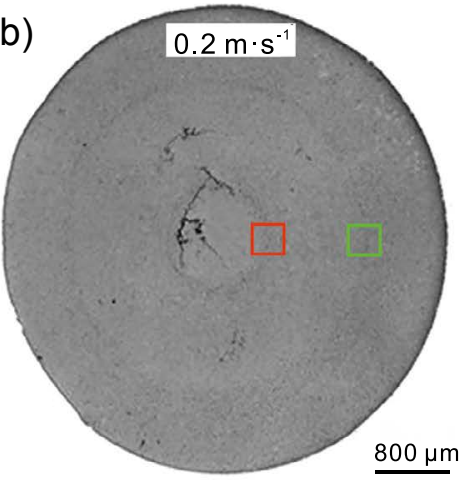

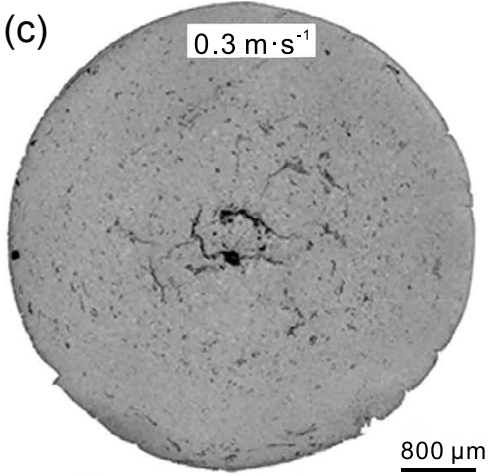

Fig. 4: OM images of typical cylinder sections of HPDC casting fabricated under low slow-shot speed of $0.1 \mathrm{~m} \cdot \mathrm{s}^{-1}(\mathrm{a})$, $0.2 \mathrm{~m} \cdot \mathrm{s}^{-1}(\mathrm{~b})$, and $0.3(\mathrm{c}) \mathrm{m} \cdot \mathrm{s}^{-1}$

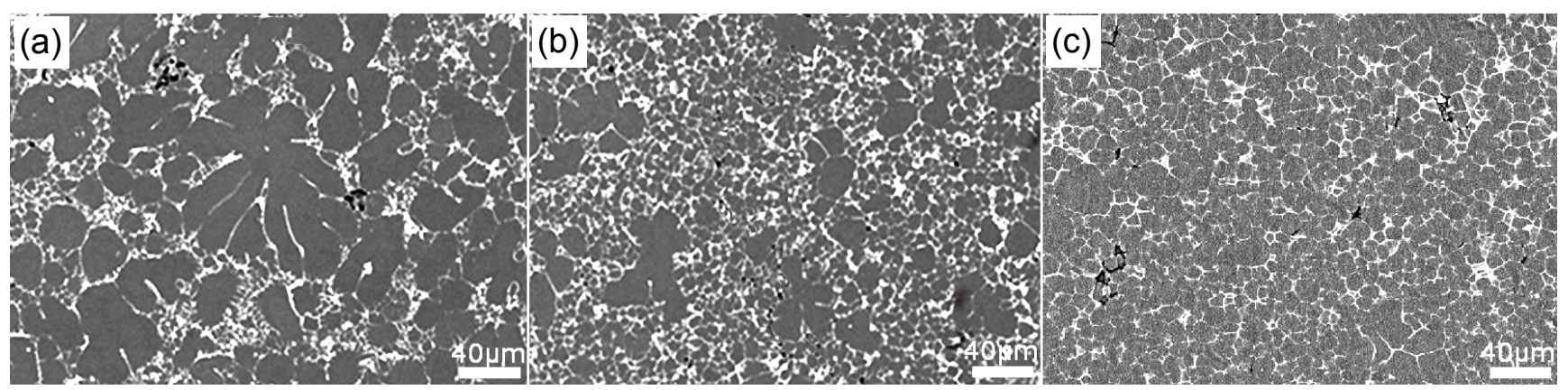

Fig. 5: Back-scattered electron images of $\mathrm{Mg}-3.0 \mathrm{Nd}-0.3 \mathrm{Zn}-0.6 \mathrm{Zr}$ alloy casting produced under the procedure featuring low slow shot speeds of $0.1 \mathrm{~m} \cdot \mathrm{s}^{-1}(\mathrm{a}), 0.2 \mathrm{~m} \cdot \mathrm{s}^{-1}$ (b), and $0.3 \mathrm{~m} \cdot \mathrm{s}^{-1}$ (c)

slow-shot speed further increases to $0.3 \mathrm{~m} \cdot \mathrm{s}^{-1}$. It has been reported that the shorter vacuum time and the stronger solidification contraction of the melt in the die cavity favor the increase of porosity volume, especially when the low slow-shot speed is higher than a certain value ${ }^{[18-19]}$. Even though longer vacuum time could reduce the gas porosity through decreasing the low slow-shot speed, more and larger aggregated dendritic ESCs flowing from the shot sleeve into the die cavity would favor the growth of shrinkage pores. Based on the above results, the optimized low slow-shot speed for HPDC Mg-3.0Nd-0.3Zn-

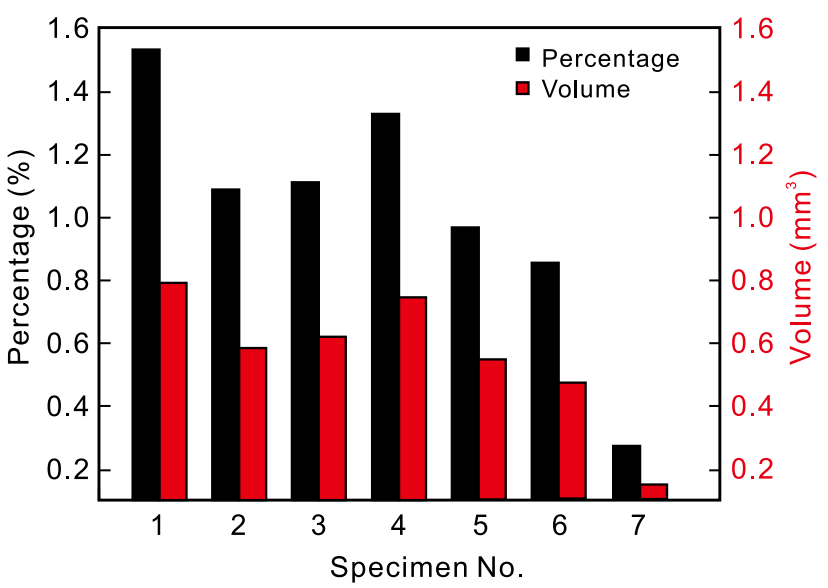

Fig. 6: Statistical results of porosity percentage and volume for different specimens (dimension of statistics is $3,299 \times$ $3,299 \times 5,166 \mu \mathrm{m}^{3}$ )
$0.6 \mathrm{Zr}$ alloy is $0.2 \mathrm{~m} \cdot \mathrm{s}^{-1}$ in this work.

Figures 7(a) and (b) show the EDS mapping results of the area marked in Fig. 4(b). No matter whether it is the inner-side or outer-side of defect bands, much higher content of $\mathrm{Nd}$ is detected. In a previous study, Zhou et al. ${ }^{[15]}$ confirmed that only $\mathrm{Mg}$ and $\mathrm{Mg}_{12} \mathrm{Nd}$ were detected through X-ray diffraction and elemental analysis. This indicates that the island-like divorced eutectic $\mathrm{Mg}_{12} \mathrm{Nd}$ particles are prone to accumulate in defect bands.

\subsection{Influence of solidification pressurization on microstructure}

Figure 8 shows the 3D reconstruction images of the castings produced without (Specimen 4) and with (Specimen 6) solidification pressurization under the low slow-shot speed of $0.1 \mathrm{~m} \cdot \mathrm{s}^{-1}$ and fast slow-shot speed of $2.0 \mathrm{~m} \cdot \mathrm{s}^{-1}$. As shown in Figs. $8\left(a_{1}-a_{3}\right)$, without pressurization, large pores are spirally distributed in the center and accompanied with a lot of dispersed small pores. The optical image in Fig. 9(a) presents very large pores with some radial lines appearing in the specimen center. However, Figs. $8\left(b_{1}-b_{3}\right)$ indicates that the porosity distribution transforms from big pores with some radial lines into a layerby-layer structure with the introduction of pressurization. The optical image shown in Fig. 9(b) indicates that an incomplete circle forms in the specimen. In addition, the remarkable difference in the volume of pores is shown in Fig. 6 . The volume of porosity decreases from $0.75 \mathrm{~mm}^{3}$ to $0.47 \mathrm{~mm}^{3}$ once the pressurization is introduced into the HPDC process. This 

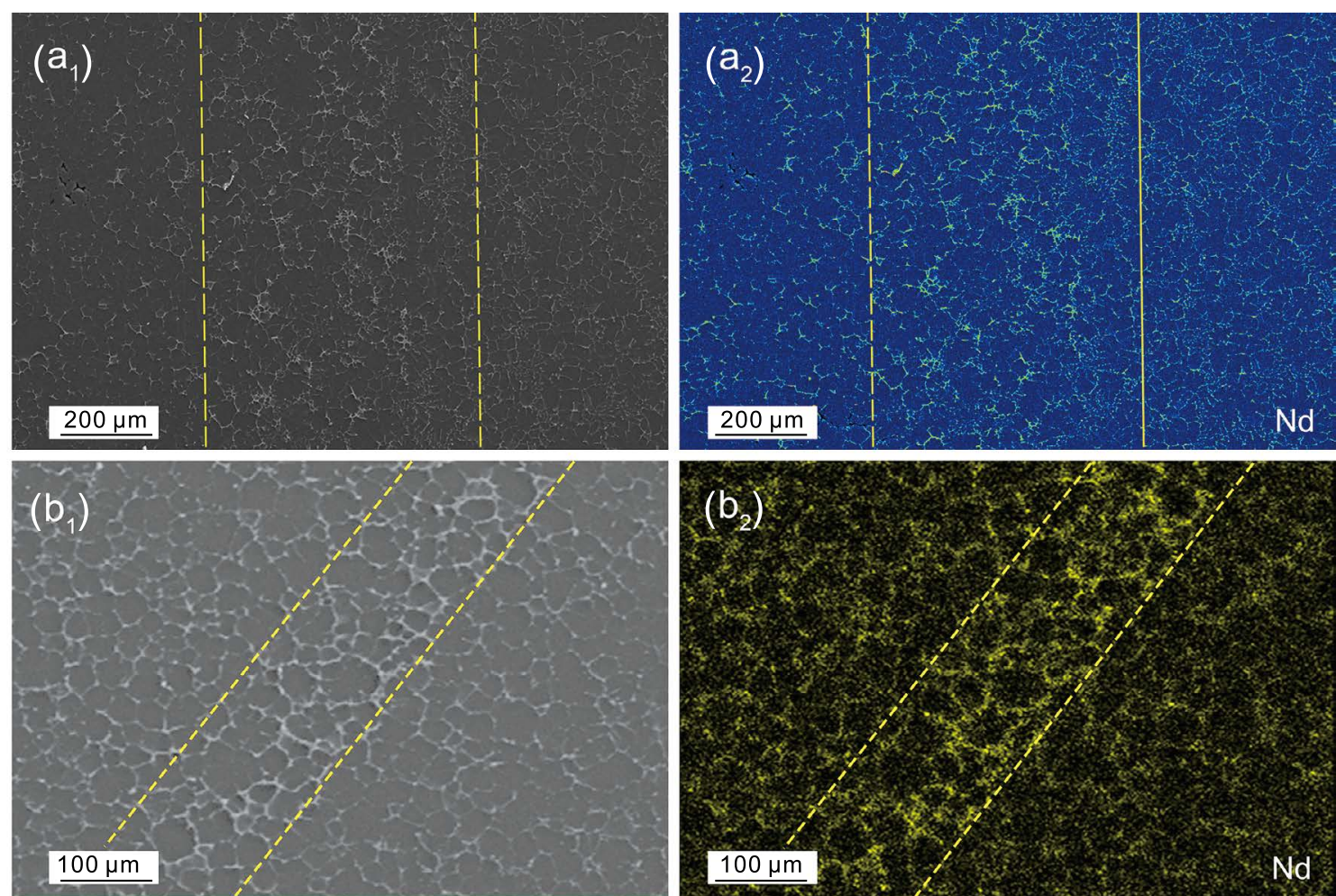

Fig. 7: Back-scattered electron images and corresponding EDS mapping of inner-side $\left(a_{1}, a_{2}\right)$ and outer-side $\left(b_{1}, b_{2}\right)$ of defect bands marked in Fig. $4(b)$

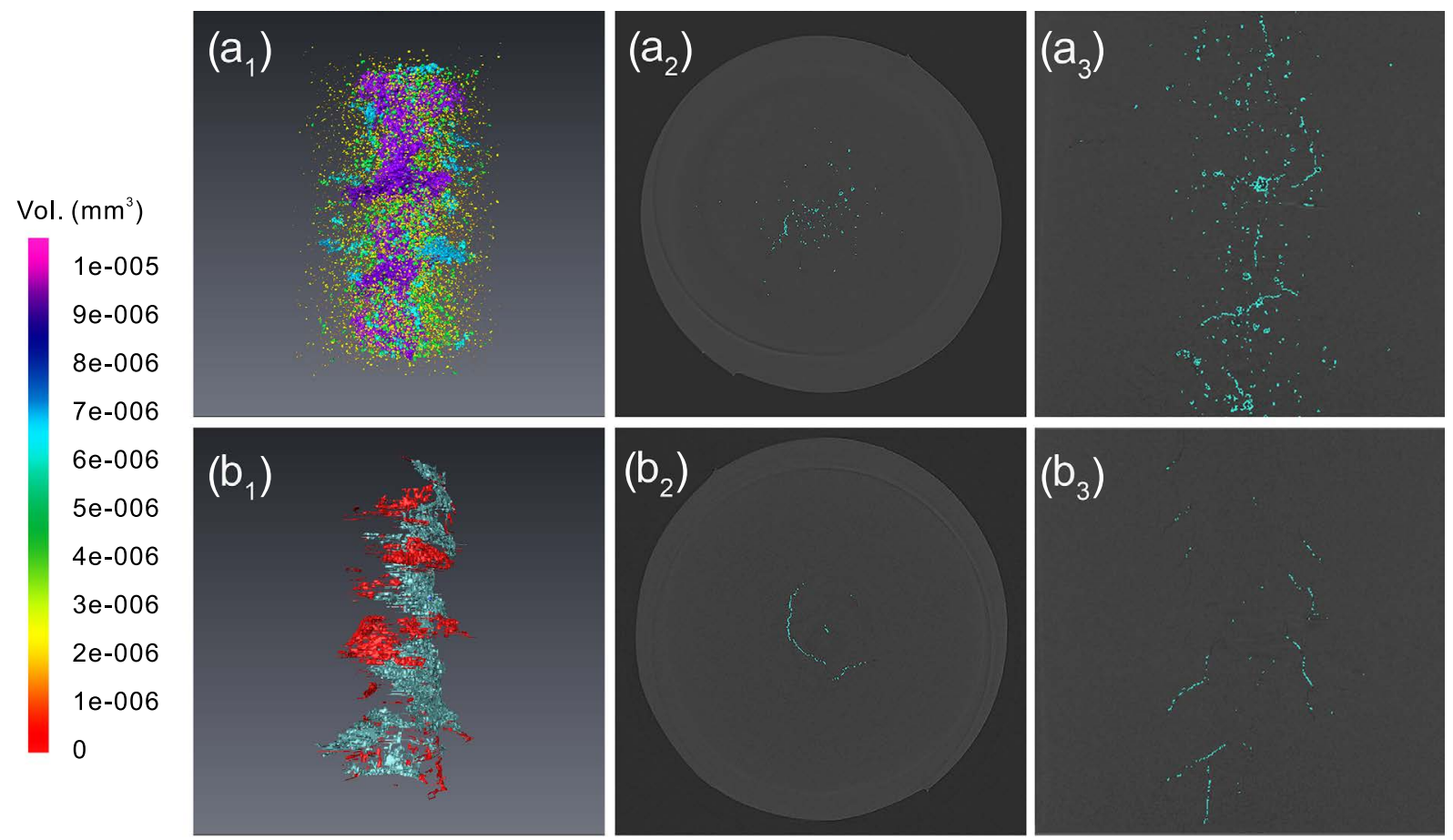

Fig. 8: 3D morphology of specimens produced without $\left(a_{1}-a_{3}\right)$ and with $\left(b_{1}-b_{3}\right)$ solidification pressurization under low slow shot speed of $0.1 \mathrm{~m} \cdot \mathrm{s}^{-1}$ and fast slow shot speed $2 \mathrm{~m} \cdot \mathrm{s}^{-1} ;\left(\mathrm{a}_{2}-\mathrm{b}_{2}\right)$ cylinder section, $\left(a_{3}-b_{3}\right)$ axial section along the metal flow direction

result indicates that pressurization could strongly optimize the liquid feeding performance during the solidification. Furthermore, the introduction of pressurization could push the defect band outwardly to the circle edge of the specimen. This is because the pressurization could enhance the interfacial heat transfer and accelerate the formation of a skin layer ${ }^{[20]}$. Subsequently, the shear force appeared between the solidified skin layer and the flow melt, which resulted in the formation of a defect band. 
(a)

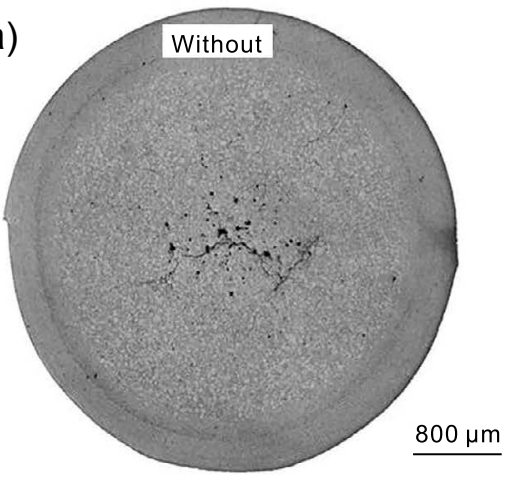

(b)

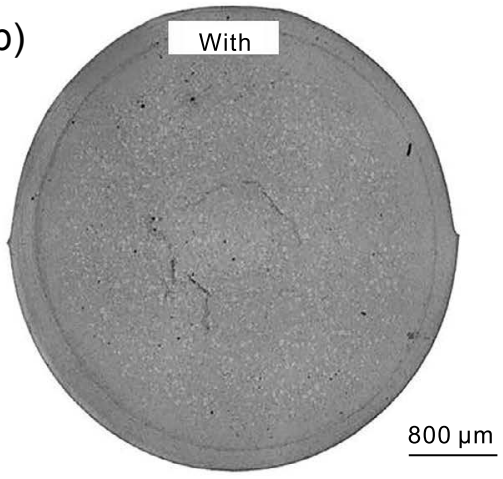

Fig. 9: OM images of typical cylinder sections of HPDC casting fabricated without (a) and with (b) solidification pressurization under low slow-shot speed of $0.1 \mathrm{~m} \cdot \mathrm{s}^{-1}$ and fast slow-shot speed of $2.0 \mathrm{~m} \cdot \mathrm{s}^{-1}$

\subsection{Influence of fast slow-shot speed on microstructure}

Figure 10 shows the 3D morphology of specimens produced under the fast slow-shot speed of $1.0,2.0$ and $3.0 \mathrm{~m} \cdot \mathrm{s}^{-1}$, respectively, and a low slow-shot speed of $0.1 \mathrm{~m} \cdot \mathrm{s}^{-1}$ under solidification pressurization. At $1.0 \mathrm{~m} \cdot \mathrm{s}^{-1}$, the pores are prone to accumulate in the center of the specimen. At $2.0 \mathrm{~m} \cdot \mathrm{s}^{-1}$ and $3.0 \mathrm{~m} \cdot \mathrm{s}^{-1}$, the central porosity dramatically decreases and transforms into large-scale spiral staggered shape along the liquid flow direction. According to the statistics in Fig. 6, the porosity volume exhibits an obvious declined trend, and its value is respectively $0.55 \mathrm{~mm}^{3}, 0.47 \mathrm{~mm}^{3}$ and $0.15 \mathrm{~mm}^{3}$. This indicates that the fast slow-shot speed can strongly reduce the porosity. Previous study has shown that the turbulent melt flow could force the ESCs to rotate and fragment when the melt was pushed into the die cavity through the ingate by the plunger ${ }^{[14,21]}$. The distances between the fragmented crystals would become smaller and facilitate the melt fulfillment. In addition, Figs. $10\left(b_{2}\right)$

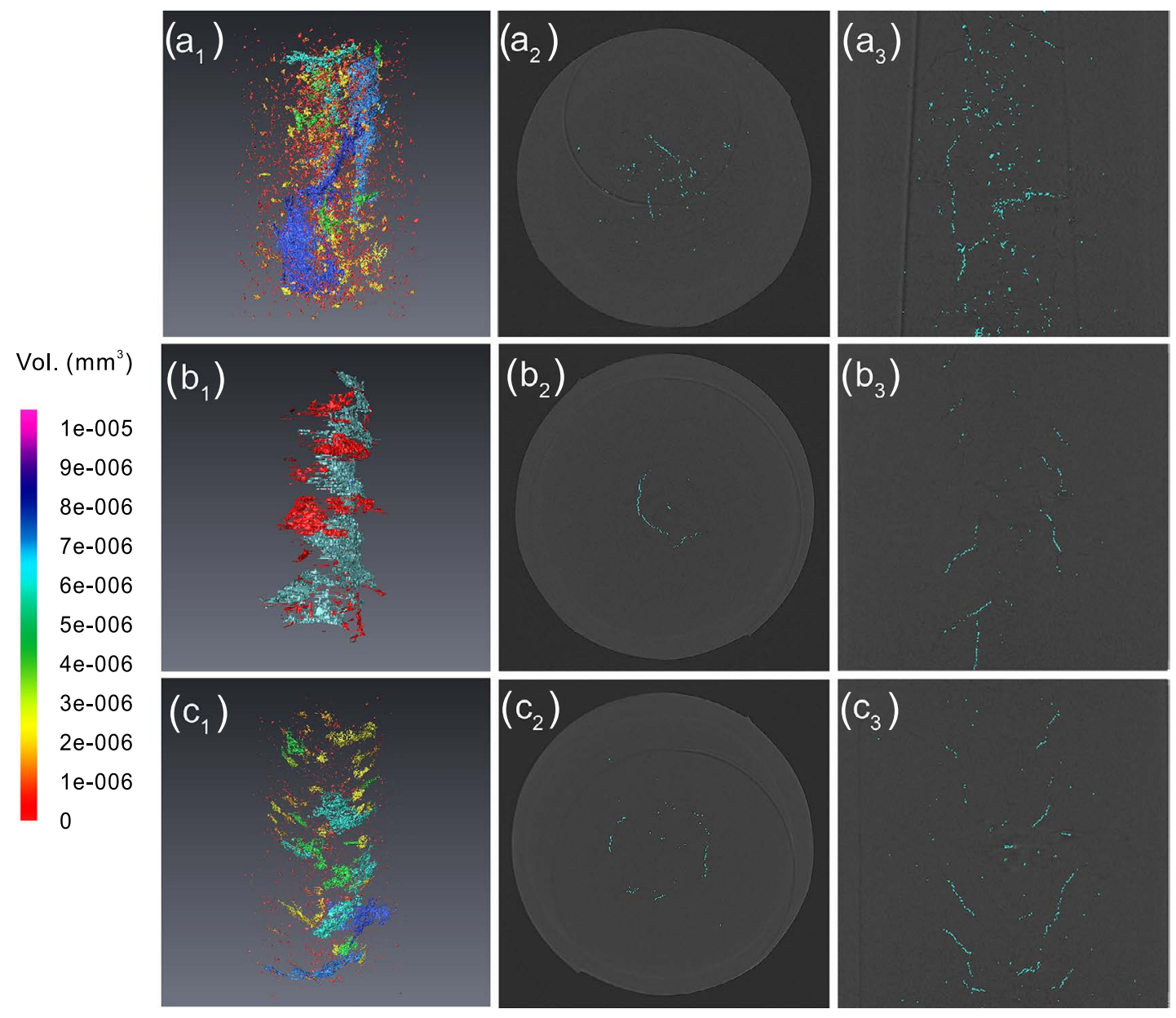

Fig. 10: 3D morphology of specimens under fast slow-shot speed of $1 \mathrm{~m} \cdot \mathrm{s}^{-1}\left(\mathrm{a}_{1}-\mathrm{a}_{3}\right), 2 \mathrm{~m} \cdot \mathrm{s}^{-1}\left(\mathrm{~b}_{1}-\mathrm{b}_{3}\right)$ and $3 \mathrm{~m} \cdot \mathrm{s}^{-1}\left(c_{1}-c_{3}\right)$ with low slow-shot speed of $0.1 \mathrm{~m} \cdot \mathrm{s}^{-1}$ and solidification pressurization, and cylinder section $\left(\mathrm{a}_{2}-\mathrm{c}_{2}\right)$, axial section along the metal flow direction $\left(\mathrm{a}_{3}-\mathrm{c}_{3}\right)$ 
and $\left(c_{2}\right)$ show that the incomplete circle of void defect spreads to the circle edge of specimens when the fast slow-shot speed increases from $2 \mathrm{~m} \cdot \mathrm{s}^{-1}$ to $3 \mathrm{~m} \cdot \mathrm{s}^{-1}$. This change is further confirmed by the OM images shown in Fig. 11. However, even though the increase of fast slow-shot speed could reduce the porosity volume, the porosity distribution becomes more dispersed, which is detrimental to the mechanical properties of the castings.
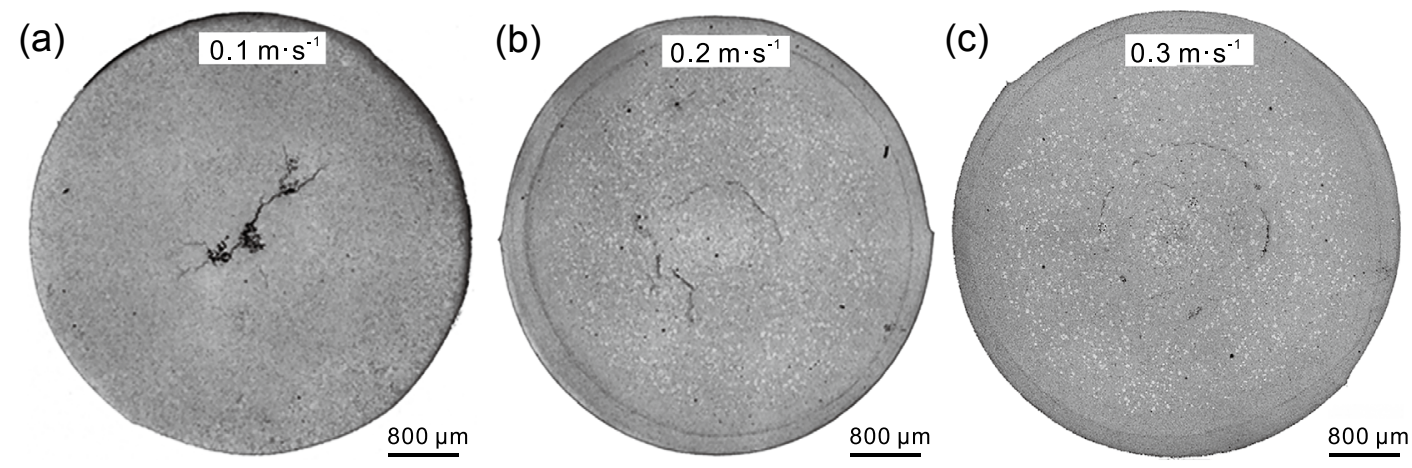

Fig. 11: OM images of typical cylinder sections of HPDC casting fabricated under fast slow-shot speed of $1 \mathrm{~m} \cdot \mathrm{s}^{-1}(\mathrm{a})$, $2 \mathrm{~m} \cdot \mathrm{s}^{-1}(\mathrm{~b})$, and $3 \mathrm{~m} \cdot \mathrm{s}^{-1}$ (c)

\section{Conclusions}

In this work, $3 \mathrm{D}$ reconstruction was used to study the correlation between the microstructural morphologies of $\mathrm{Mg}$ 3.0Nd-0.3Zn-0.6Zr alloy castings and different high pressure die casting (HPDC) process parameters. The following conclusions can be drawn:

(1) Under the procedure with low slow-shot speed of $0.1,0.2$ and $0.3 \mathrm{~m} \cdot \mathrm{s}^{-1}$ without fast slow shot speed and solidification pressurization, porosities concentrate in the center of the specimens with one spiral staggered shape along the liquid flow direction. Meanwhile, the porosities become much more dispersed with the increasing low slow-shot speed. The porosity volume decreases from $0.8 \mathrm{~mm}^{3}$ to $0.59 \mathrm{~mm}^{3}$ when the low slow-shot speed increases from $0.1 \mathrm{~m} \cdot \mathrm{s}^{-1}$ to $0.2 \mathrm{~m} \cdot \mathrm{s}^{-1}$, while the value slightly increases to $0.62 \mathrm{~mm}^{3}$ at $0.3 \mathrm{~m} \cdot \mathrm{s}^{-1}$ due to the shorter vacuum time and stronger solidification contraction of melt in the die cavity. At $0.2 \mathrm{~m} \cdot \mathrm{s}^{-1}$, the island-like divorced eutectic $\mathrm{Mg}_{12} \mathrm{Nd}$ particles are prone to accumulate and form the inner-side and outer-side defect bands.

(2) Under the low slow-shot speed of $0.1 \mathrm{~m} \cdot \mathrm{s}^{-1}$ and fast slow-shot speed $2.0 \mathrm{~m} \cdot \mathrm{s}^{-1}$, the introduction of solidification pressurization could strongly reduce the porosity volume from $0.75 \mathrm{~mm}^{3}$ to $0.47 \mathrm{~mm}^{3}$ due to the better liquid feeding performance. Meanwhile, the dispersed pores transform into a layer-by-layer structure and the defect band is pushed outward to the outside edge of the specimen.

(3) Under the low slow shot-speed of $0.1 \mathrm{~m} \cdot \mathrm{s}^{-1}$ and solidification pressurization, fast slow-shot speed could also remarkably decrease the porosity volume and its value is respectively $0.55 \mathrm{~mm}^{3}, 0.47 \mathrm{~mm}^{3}$ and $0.15 \mathrm{~mm}^{3}$ at $1.0 \mathrm{~m} \cdot \mathrm{s}^{-1}$, $2.0 \mathrm{~m} \cdot \mathrm{s}^{-1}$ and $3.0 \mathrm{~m} \cdot \mathrm{s}^{-1}$. With an increase in fast slow-shot speed from $1.0 \mathrm{~m} \cdot \mathrm{s}^{-1}$ to $3.0 \mathrm{~m} \cdot \mathrm{s}^{-1}$, the porosities gathered in the center decrease and transform from big pores with some radial lines into a large-scale spiral staggered shape along the liquid flow direction. However, the porosity becomes more dispersed as the speed increases from $2.0 \mathrm{~m} \cdot \mathrm{s}^{-1}$ to $3.0 \mathrm{~m} \cdot \mathrm{s}^{-1}$.

\section{Acknowledgements}

This work was financially supported by the National Training Programs of Innovation and Entrepreneurship for Undergraduates and the State Key Lab of Advanced Metals and Materials (No. 2021-ZD08), and also by the National Natural Science Foundation of China (No. 52175284). Thanks to the technical support of BL13W1 Beamline in Shanghai Synchrotron Radiation Facility (SSRF) and Gaomi Xiangyu company.

\section{References}

[1] Yamagata $\mathrm{H}$. The science and technology of materials in automotive engines. Elsevier, 2015.

[2] Qin X Y, Su Y, Chen J, et al. Finite element analysis for die casting parameters in high-pressure die casting process. China Foundry, 2019, 16(4): 272-276.

[3] Joost W J and Krajewski P E. Towards magnesium alloys for high-volume automotive applications. Scripta Materialia, 2017, 128 (Supplement C): 107-112.

[4] Zhang J H, Zhang M L, Meng J, et al. Microstructures and mechanical properties of heat-resistant high-pressure die-cast Mg-4Al-xLa-0.3 mn $(x=1,2,4,6)$ alloys. Materials Science and Engineering A, 2010, 527(10-11): 2527-2537.

[5] Ma C S, Yu W B, Pi X F, et al. Study of Mg-Al-Ca magnesium alloy ameliorated with designed Al8Mn4Gd phase. Journal of Magnesium and Alloys, 2020, 8(4): 1084-1089.

[6] Zhang X B, Yuan G Y, Niu J L, et al. Microstructure, mechanical properties, biocorrosion behavior, and cytotoxicity of asextruded $\mathrm{Mg}-\mathrm{Nd}-\mathrm{Zn}-\mathrm{Zr}$ alloy with different extrusion ratios. Journal of the Mechanical Behavior of Biomedical Materials, 2012, 9: 153-162.

[7] Li X B, Xiong S M, and Guo Z P. Improved mechanical properties in vacuum-assist high-pressure die casting of AZ91D alloy. Journal of Materials Processing Technology, 2016, 231: 1-7.

[8] Weiler J P, Wood J T, Klassen R J, et al. Relationship between internal porosity and fracture strength of die-cast magnesium AM60B alloy. Materials Science and Engineering A, 2005, 395(1-2): 315-322. 
[9] Song J, Xiong S M, Li M, et al. The correlation between microstructure and mechanical properties of high-pressure die-cast AM50 alloy. Journal of Alloys and Compounds, 2009, 477(1-2): 863-869.

[10] Biswas S, Sket F, Chiumenti M, et al. Relationship between the 3D porosity and $\beta$-phase distributions and the mechanical properties of a high pressure die cast AZ91 Mg alloy. Metallurgical and Materials Transactions A, 2013, 44(9): 43914403.

[11] Lee S G and Gokhale A M. Formation of gas induced shrinkage porosity in Mg-alloy high-pressure die-castings. Scripta Materialia, 2006, 55(4): 387-390.

[12] Lee S G, Patel G R, Gokhale A M, et al. Variability in the tensile ductility of high-pressure die-cast AM50 Mg-alloy. Scripta Materialia, 2005, 53(7): 851-856.

[13] Lee S G, Patel G R, Gokhale A M, et al. Quantitative fractographic analysis of variability in the tensile ductility of high-pressure die-cast AE44 Mg-alloy. Materials Science and Engineering A, 2006, 427(1-2): 255-262.

[14] Yu W B, Ma C S, Ma Y H, et al. Correlation of 3D defect-band morphologies and mechanical properties in high pressure die casting magnesium alloy. Journal of Materials Processing Technology, 2020, 288: 116853.

[15] Zhou Y, Guo Z, and Xiong S M. et al. Effect of runner design on the externally solidified crystals in vacuum die-cast Mg-3.0Nd$0.3 \mathrm{Zn}-0.6 \mathrm{Zr}$ alloy. Journal of Materials Processing Technology, 2019, 267: 366-375.
[16] Wang B S and Xiong S M. Effects of shot speed and biscuit thickness on externally solidified crystals of high-pressure diet cast AM60B magnesium alloy. Transactions of Nonferrous Metals Society of China, 2011, 21(4): 767-772.

[17] Yu W B, Yuan Z, Guo Z P, et al. Characterization of A390 aluminum alloy produced at different slow shot speeds using vacuum assisted high pressure die casting. Transactions of Nonferrous Metals Society of China, 2017, 27(12): 2529-2538.

[18] Yu W B, Cao Y, Li X. et al. Determination of interfacial heat transfer behavior at the metal/shot sleeve of high pressure die casting process of AZ91D Alloy. Journal of Materials Science and Technology, 2017, 33(1): 52-58.

[19] Lee S G, Gokhale A M, Patel G R, et al. Effect of process parameters on porosity distributions in high-pressure die-cast AM50 Mg-alloy. Materials Science and Engineering A, 2006, 427(1): 99-111.

[20] Guo Z P and Xiong S M. Relationship between metal-die interfacial heat transfer coefficient and casting solidification rate in high pressure die casting process. Acta Metallurgica Sinica, 2009, 45(1): 102-106.

[21] Li X B, Yu W B, Wang J S, et al. Influence of melt flow in the gating system on microstructure and mechanical properties of high pressure die casting AZ91D magnesium alloy. Materials Science and Engineering, 2018, 736: 219-227. 